\title{
Wind-induced cladding and structural loads on low-rise buildings with 4:12-sloped hip roofs
}

\author{
Shuai Shao ${ }^{\mathrm{a}}$, Yuji Tian ${ }^{\mathrm{b}, \mathrm{d}}$, Qingshan Yang ${ }^{\mathrm{c}, \mathrm{d}}$, Ted Stathopoulos ${ }^{\mathrm{e}}$ \\ a China Electric Power Research Institute, Beijing, 100192, China \\ ${ }^{\mathrm{b}}$ School of Civil Engineering, Beijing Jiaotong University, Beijing, 100044, China \\ ${ }^{\mathrm{c}}$ School of Civil Engineering, Chongqing University, Chongqing, 400044, China \\ d Beijing's Key Laboratory of Structural Wind Engineering and Urban Wind Environment, Beijing, 100044, China \\ ${ }^{\mathrm{e}}$ Centre for Zero Energy Building Studies, Department of Building, Civil, and Environmental Engineering, \\ Concordia University, Montreal, H3G 1M8, Canada
}

Abstract: The characteristics of cladding and structural loads for 4:12-sloped hiproofed low-rise buildings with rectangular, L- and T-shaped plans are examined, based on wind tunnel data and three-dimensional linear computational models. Regarding cladding loads, the rectangular gable roof incurs more considerable local suction, compared with the rectangular hip roof. However, due to building plan configurations, intense suction and positive pressure are distinctly distributed on roofs and walls around building re-entrant corners of hip-roofed non-rectangular buildings. Considering structural loads, very high pressures act on the gable-roofed end frame, compared with those on the corresponding hip-roofed frames. Furthermore, the building plan impact on structural load patterns varying with wind directions and on most critical values is clear. Particularly, the most critical structural loads acting on intermediate and penultimate frames of wings of L-shaped hip-roofed buildings and side wings of Tshaped cases, show a 25\% maximum increase. However, regarding the central wings of T-shaped buildings, results generally fall within the same range with those of the rectangular and L-shaped buildings. In addition, the structural connections and boundary conditions significantly influence structural load magnitudes and distribution shapes. Finally, the effect of horizontal aspect ratios on both cladding and structural loads is found to be minimal.

Keywords: wind-induced pressures; cladding loads; structural loads; hip-roofed; lowrise buildings; L- and T-shaped; wind tunnel test; finite element model 


\section{Introduction}

Wind-induced cladding and structural loads acting on building external surfaces and the main wind force-resisting system (MWFRS) are of interest in the engineering design of low-rise buildings. Generally, intense wind pressures appear on some local areas of cladding (Kopp and Morrison 2018). Extensive studies of wind loads on cladding have been performed to evaluate various influential parameters, in which the building geometry (e.g., roof shape, roof slope, building dimensions, etc.) plays an important role on wind load distributions. However, most previous studies focused on rectangular low buildings (e.g., Holmes 1983; Stathopoulos 1984a; Meecham et al. 1991; Holmes 1994; Hoxey and Robertson 1994; Lin et al. 1995; Case and Isyumov 1998; Gavanski et al. 2013; Gavanski and Uematsu 2014; Alrawashdeh and Stathopoulos 2015; Duthinh et al. 2018; Kopp and Morrison 2018). With a few exceptions, limited attention has been paid to local cladding loads of non-rectangular low-rise buildings. Stathopoulos and Zhou (1993) proposed a numerical model to predict turbulent wind pressures for a symmetrical flat-roofed L-shaped building. Kikuchi et al. (2001) investigated local peak pressures acting on roofs and walls of Lshaped flat-roofed low- and mid-rise building models. Parackal et al. (2016) and Shao et al. (2018) performed studies about cladding pressures on hip roofs with complex Lor T-shaped plan views. Therefore, the comprehensive features of wind loads on both roof and wall cladding of non-rectangular low buildings with hip roofs remain an open question.

In addition to the cladding loads, the structural loads acting on the MWFRS are even more significant for the wind-resisting ability of entire buildings. Basically, the structural wind loads depend on many factors, pertaining to applied cladding wind loads (which are affected by building geometries) and structural system characteristics (e.g., structural arrangements, connection conditions, relative stiffness of structural members etc.). Commonly, steel frames are widely used for the construction of low-rise buildings, 
which are sensitive to wind loads due to their light weight. The building representation of steel buildings by using Finite Element Method has been developed in past decades to examine the wind-induced performance of MWFRS. Specifically, the wind-resisting ultimate strength of two-dimensional (2D) bare frames of gable-roofed buildings was analyzed by nonlinear models (e.g., Jang 2004; Duthinh and William 2007; Duthinh et al. 2008). In addition, the internal forces including bending moments and shear forces acting on bare frames of MWFRS were also obtained based on wind tunnel test data by influence line coefficients (Kopp et al. 2005; St. Pierre et al. 2005; Coffman et al. 2009; Ginger et al. 2015; Habte et al. 2017; Feng and Chen 2018). Actually, the previously mentioned studies mainly concentrated on the performance of 2D frames neglecting the impact of cladding and secondary members (purlins and girts) to add conservatism to the design. However, the interaction of all structural members is complex; it influences the wind load sharing path and, further, it has a great contribution to wind resistance (Yang and Bai 2017). Consequently, in order to find a more adequate prediction of the entire steel building systems, three-dimensional (3D) models were considered including cladding (roof/wall sheeting), secondary members (purlins and girts) and main frames (e.g., Sockalingam 1995; Mahendran and Moor 1999; Wrzesien et al. 2015). Nonetheless, the results above were determined by applying a given wind loading condition rather than a real loading case. Moreover, the building configurations were simply characterized by rectangular buildings with gable roofs, and plane portal frames comprising columns and horizontal or pitched rafters (depending on roof slopes) were used. In contrast, extending to the hip-roofed or non-rectangular cases, the plane portal frames would not be applicable, particularly for the hip-end building components. In this case, hip and jack rafters, out of the planes of columns, are commonly constructed. Therefore, both the structural arrangements and their envelope geometries are changed for the irregular buildings with hip roofs, relative to those with gable roofs. Accordingly, how the MWFRS of hip-roofed buildings performs under real extreme wind loads is of interest but has received little attention. 
In light of this, the paper aims to comprehensively examine the wind load distribution on cladding surfaces of non-rectangular (L- and T-shaped) low-rise buildings with hip roofs, based on wind tunnel test data. Furthermore, by applying surface wind load information in 3D finite element models, the corresponding structural load distribution characteristics are presented for such building configurations. Through comparisons, the effects of roof shape, building plan, horizontal aspect ratio, and connection/boundary conditions are investigated and provide useful theoretical supplements for current structural wind-resisting design.

\section{Experimental data}

The experimental data obtained from the boundary layer wind tunnel at the Building Aerodynamics Laboratory, Concordia University, were used in this study. The working section of the blow-down open-circuit wind tunnel is $1.80 \mathrm{~m}$ in width, $12.2 \mathrm{~m}$ in length with an adjustable roof height ranging from $1.40 \mathrm{~m}$ to $1.80 \mathrm{~m}$. Detailed information about the wind tunnel construction and consideration details are presented by Stathopoulos (1984b).

\subsection{Atmospheric boundary layer and terrain exposure simulation}

Generally, mean wind pressures on low buildings are higher in the open country exposure, compared with those in suburban terrains. However, the fluctuating pressure components are higher with the increased turbulence of the suburban exposure. Based on past experience, the codification results originated primarily from models in open country exposure because this gave generally more critical pressure coefficients. Therefore, the open country exposure was selected to be examined in this study.

The mean wind velocity is assumed to satisfy the power law profile with an exponent $\alpha$ of 0.15 . Figure 1 summarizes the profiles of the mean wind velocity $\left(\bar{V}_{\mathrm{Z}} / \bar{V}_{\mathrm{G}}\right)$, referenced by at the gradient height $\left(Z_{\mathrm{G}}=60 \mathrm{~cm}\right)$ and longitudinal turbulence intensity $\left(I_{U}\right)$, compared with those determined according to Engineering Science Data Unit (ESDU 1982). It indicates generally good agreement for both velocity and 
turbulence intensity profiles for the current exposure terrain.

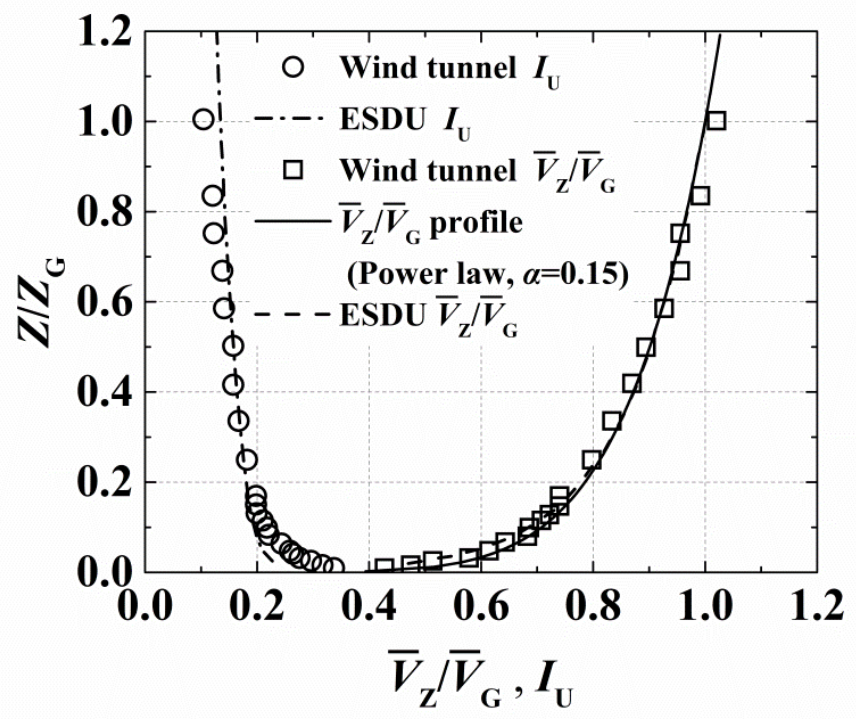

Fig. 1 Mean wind velocity $\left(\bar{V}_{Z} / \bar{V}_{G}\right)$ and turbulence intensity $\left(I_{\mathrm{U}}\right)$ profiles for current simulated open country exposure terrains.

\subsection{Building configurations}

Eight building models were built at a permissible geometrical scale of 1:200, including rectangular cases with gable (Ref. name: RG), hip roofs (Ref. names: RH1, 2) and L-/T-shaped hip-roofed cases (Ref. names: LH1, 2 and TH1, 2, 3), as illustrated in Table 1. Note that considering the geometrical characteristics and anticipated result differences, the side and central wings of T-shaped building modes are investigated and denoted as $\mathrm{TH}(\mathrm{S})$ and $\mathrm{TH}(\mathrm{C})$, (see Table 1). All building models, with the intermediate roof slopes of $4: 12\left(18.4^{\circ}\right)$, have an equivalent mean roof height $(h)$ of $5.8 \mathrm{~m}$ and horizontal dimensions ranging from $10 \mathrm{~m}$ to $30 \mathrm{~m}$ in full scale.

\subsection{Pressure measurements and pressure coefficients}

The pressure fluctuations on the end components of building models were measured by the gable- and hip-roofed tested models [as seen in Fig. 2 (a)], equipped with 64 and 144 pressure taps, respectively. Pressure taps have been deliberately concentrated on roof edge, ridge and corner areas, where the most critical suctions are anticipated. Based on the pressure distributions of these wind tunnel data and those of 
related other studies (e.g., Parackal et al. 2016), the occurrences of more critical roof suctions on the current buildings are not really likely. Furthermore, the high density of pressure taps and the variety of building configurations examined would not allow space for tubing to accommodate additional taps. The test models are combined with the uniform-sized component models [as seen in Fig. 2 (b)], to construct the complete rectangular, L-shaped, or T-shaped models - see Fig. 2 (c). For each test model with pressure taps, the investigated wind directions $(\theta)$ were taken from $0^{\circ}$ to $350^{\circ}$ with regular $10^{\circ}$ increments and particular $5^{\circ}$ increments at the four diagonal directions (i.e., $45^{\circ}, 135^{\circ}, 225^{\circ}$ and $315^{\circ}$ ). The $0^{\circ}$ and $90^{\circ}$ wind directions correspond to the directions perpendicular to side and end walls of tested models, respectively, as indicated in Table 1. Note that regarding the central wings of T-shaped models, $\theta$ starts at the left side wall and increases in a counterclockwise direction. The measured wind pressure was scanned at the sampling rate of $300 \mathrm{~Hz}$ (300 samples per second) for 27 seconds on the wind-tunnel scale. By assuming a velocity scale in the wind tunnel of about 1:3, the resulting full-scale pressure time history was 0.5 hour.

The collected fluctuating pressure coefficient $C_{\mathrm{P}}(t)$ for each pressure tap on building surfaces was normalized by the mean velocity pressure $\left(0.5 \rho \bar{V}_{h}^{2}\right)$ measured at the mean roof height and defined as,

$$
C_{\mathrm{P}}(t)=\frac{P(t)-P_{0}}{0.5 \rho \bar{V}_{h}^{2}}
$$

where $P(t)$ and $P_{0}$ are the measured pressure time history and the static pressure, respectively; $\bar{V}_{h}$ is the mean wind velocity at mean roof height; and $\rho$ is the air density. 
Table 1 Experimental configurations: Building dimensions, pressure tap layout and wind direction $(\theta)$

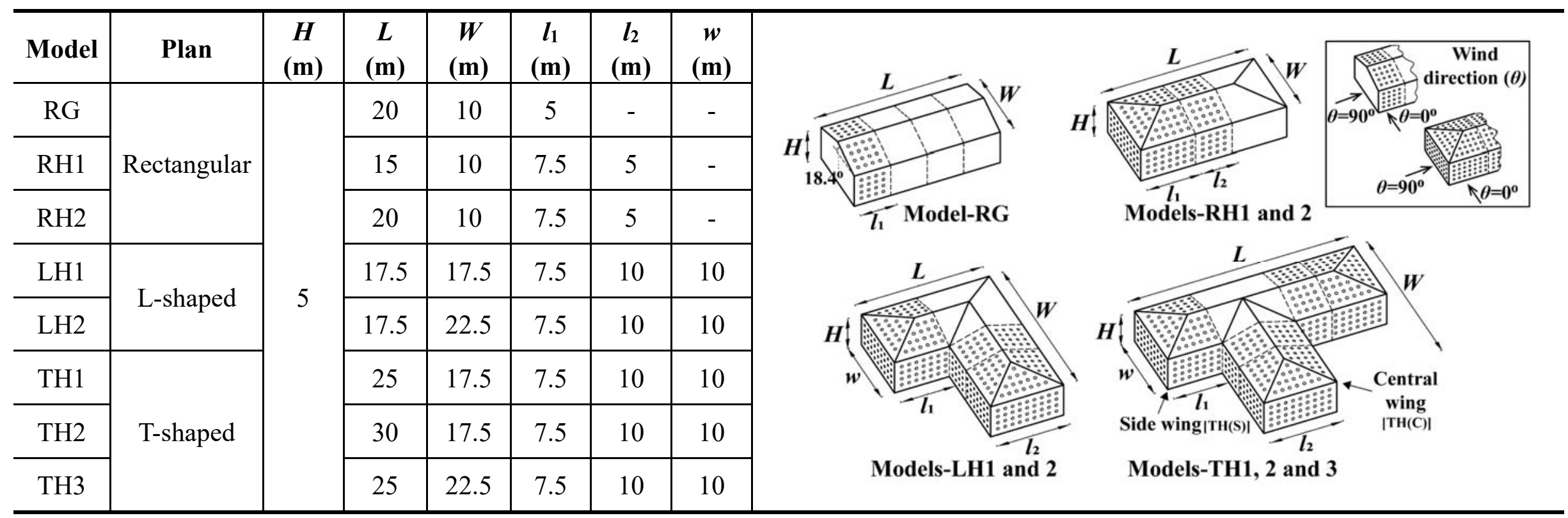


(a)

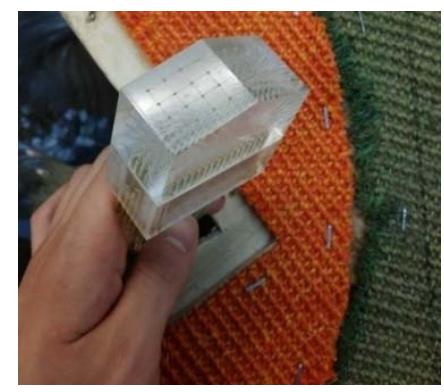

(b)

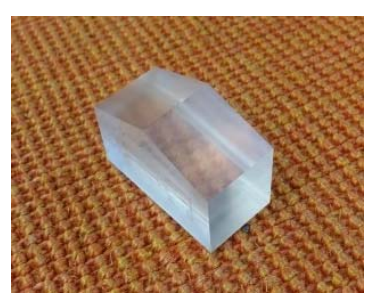

(c)
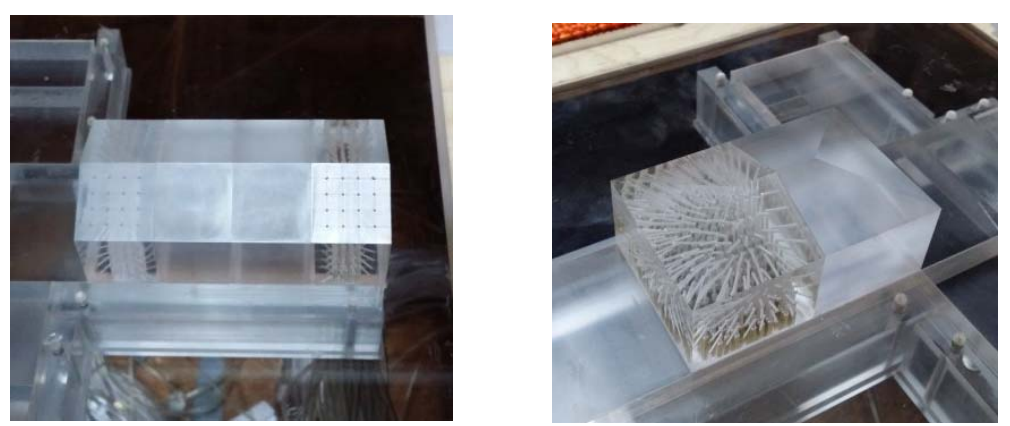
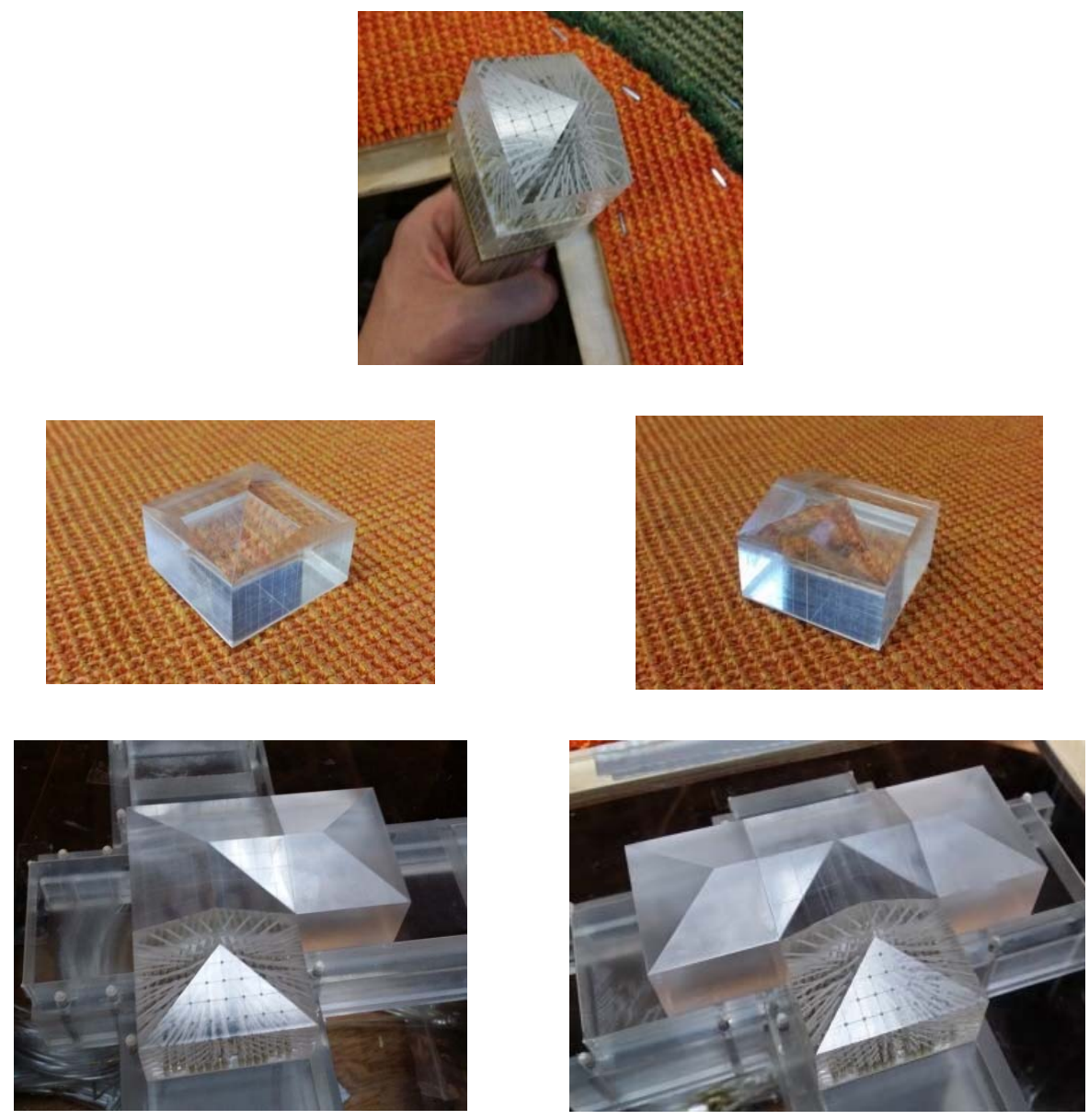

Fig. 2 Experimental building models: (a) tested models with pressure taps, (b) component models without pressure taps, (c) complete building models 


\section{Numerical simulation}

\subsection{Structural system}

The structural system of steel portal frames is applied in the current study, based on related design manuals (Salter et al. 2004), as shown by Fig. 3. Regarding the rectangular gable-roofed building, the moment-resisting frames are equally spaced at a regular interval of $5 \mathrm{~m}$ and plotted by heavy lines. For each end wing of hip-roofed building models, the MWFRS includes end, intermediate and penultimate frames [see Fig. 3 (b)]. Roof and wall cladding are fastened to purlins and girts which are connected to the MWFRS. Furthermore, the structural loads in the directions along the out-offrame planes have not been considered, hence bracing is not included.

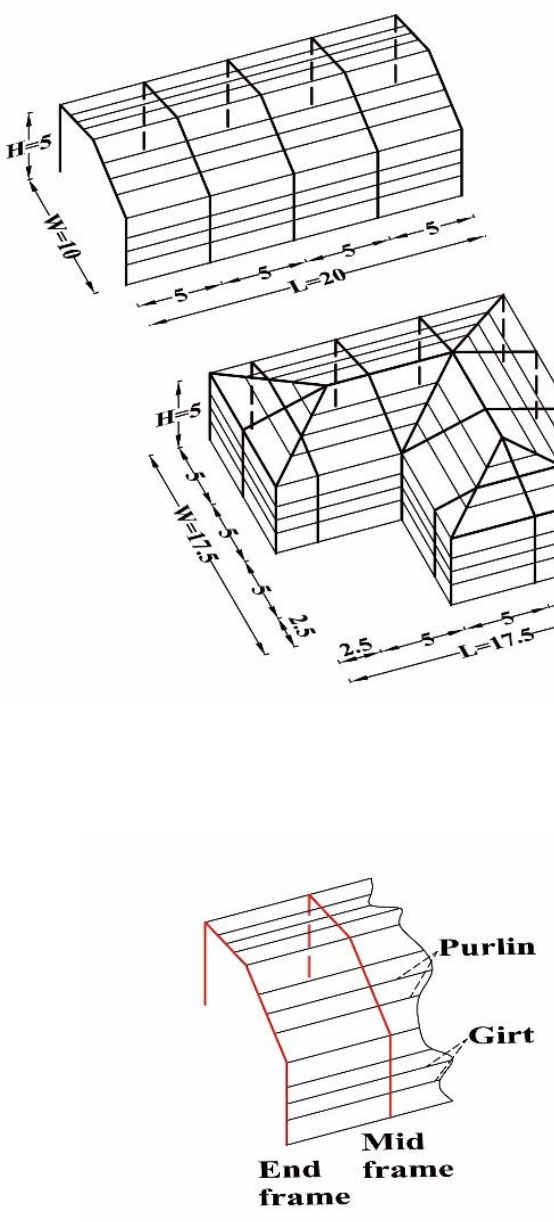

Gable-end component

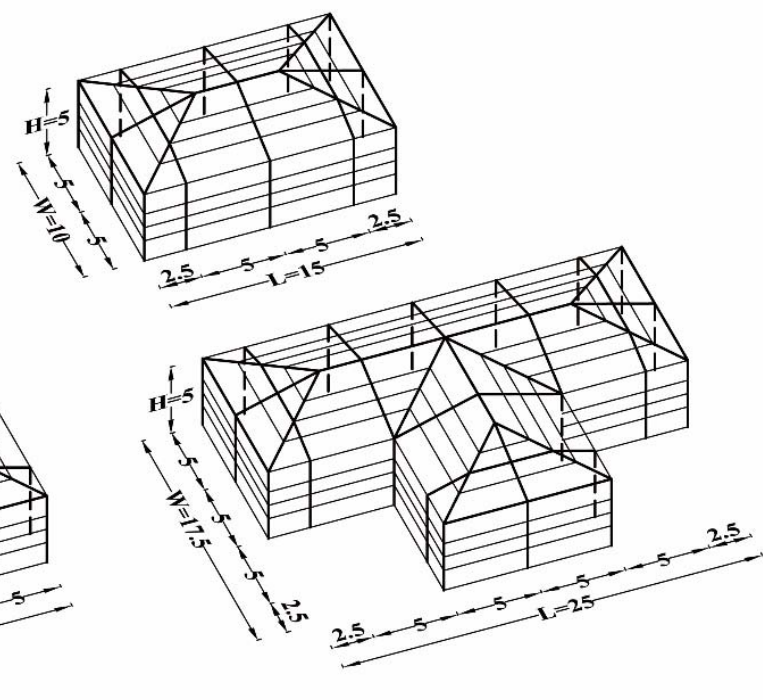

(a)

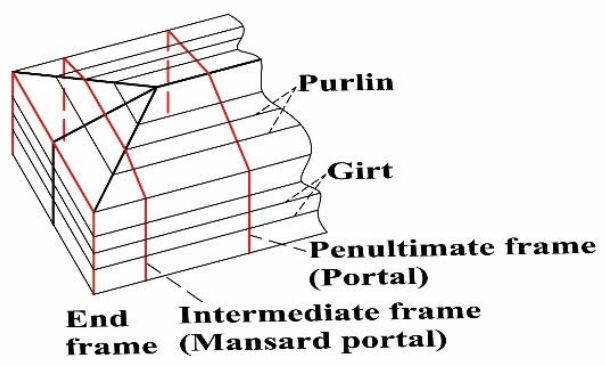

Hip-end component

(b)

Fig. 3 Frame system: (a) Structural arrangement, (b) Structural definition 


\subsection{Finite Element models}

Based on the aforementioned structural configurations, 3D linear Finite Element models are generated by the commercial software ABAQUS (2014) for the truncated end components of gable- and hip-roofed buildings, as seen in Fig. 4. Note that the roof and wall cladding are modeled but not shown. The rigid main frames and secondary members (purlin and girts) are formed using "wire" elements and I-shaped sections with different commonly-used dimensions (Salter et al. 2004) as shown in Table 2. The roof and wall cladding are reduced to the plate with a uniform thickness and modeled as a "shell" element. In terms of modeling of joint conditions, the exact behavior has been proved to be relatively between ideally pinned or fully rigid (Díaz et al. 2011). In order to cover more comprehensive results, two particular cases with different connection conditions are considered for current models, namely, the pinned and fixed cases. Specifically, for the pinned case, the structural systems are pinned-supported on the boundary. The connection between a secondary member and a main frame is coupled and articulated for freedom of rotation around the section principal axis (as demonstrated by the "1" direction in the section sketch of Table 2). Similarly, the roof and wall cladding are supported by purlins or girts with pin-rollers, which allow rotations along the axis of the corresponding secondary members (Wu et al. 2015). On the contrary, the fixed cases use rigid links for all boundary and connection conditions. The validity of the current modeling method and sensitivity have been examined to be reliable by comparing with ideal statically determinate three-pinned portal frames, which is not shown herein. 


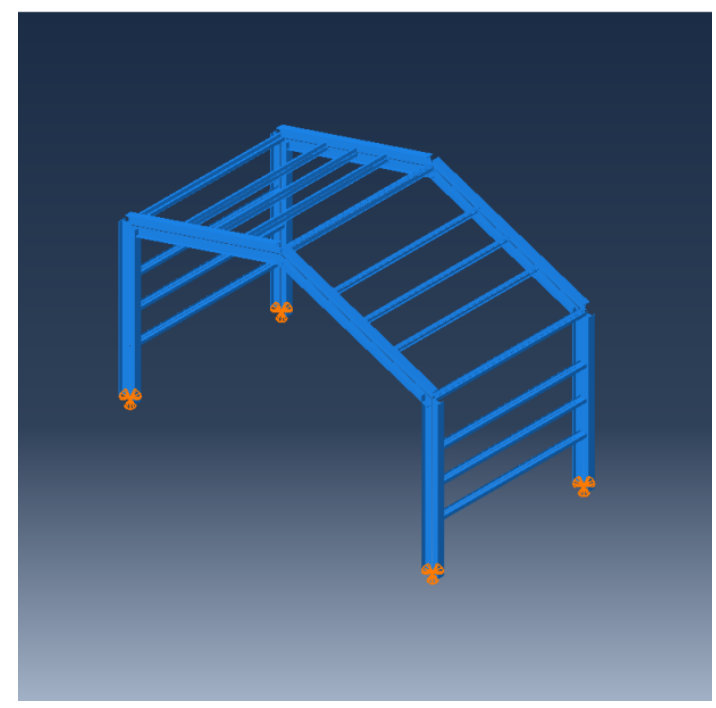

(a)

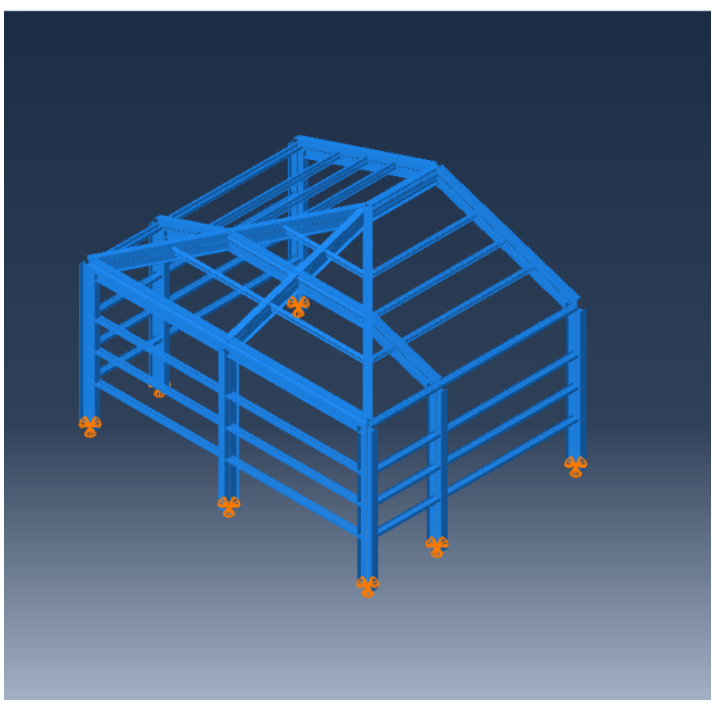

(b)

Fig. 4 Wireframe of three-dimensional Finite Element models: (a) gable-roofed building component, (b) hip-roofed building component.

Table 2 Section profiles for structural members

\begin{tabular}{c|c|c|c|c|c|c|c|c}
\hline $\begin{array}{c}\text { Section } \\
\text { sketch }\end{array}$ & $\begin{array}{c}\text { Structural } \\
\text { member }\end{array}$ & $\begin{array}{c}\mathbf{I} \\
(\mathrm{m})\end{array}$ & $\begin{array}{c}\mathbf{h} \\
(\mathrm{m})\end{array}$ & $\begin{array}{c}\mathbf{b 1} \\
(\mathrm{m})\end{array}$ & $\begin{array}{c}\mathbf{b 2} \\
(\mathrm{m})\end{array}$ & $\begin{array}{c}\mathbf{t 1} \\
(\mathrm{m})\end{array}$ & $\begin{array}{c}\mathbf{t 2} \\
(\mathrm{m})\end{array}$ & $\begin{array}{c}\mathbf{t 3} \\
(\mathrm{m})\end{array}$ \\
\hline & $\begin{array}{c}\text { Main } \\
\text { frame }\end{array}$ & 0.26835 & 0.5367 & 0.21 & 0.21 & 0.0174 & 0.0174 & 0.0108 \\
\cline { 2 - 9 } & $\begin{array}{c}\text { Purlin/ } \\
\text { girt }\end{array}$ & 0.11 & 0.22 & 0.1 & 0.1 & 0.0025 & 0.0025 & 0.0025 \\
\hline
\end{tabular}

\subsection{Force/moment coefficients}

By distributing the wind pressure information on the cladding (shell elements) of the Finite Element models created in the previous section, wind loads are transferred through secondary members on main frames and then induce frame internal forces. For each pressure tap, there is a corresponding tributary area on which the measured pressure coefficient time history $\left[C_{\mathrm{P}}(t)\right]$ is assumed to act. Specifically, the tributary area is divided by the midway lines between the adjacent rows and column of pressure taps (Main and Fritz 2006). The method to assign tap pressures to a specific tributary area may influence the final wind-induced force results. However, the impact of a relatively reasonable zoning method may be moderate because the main structural 
frame responses to highly-localized pressures with large fluctuations acting on several surfaces are attenuated by the decrease of full spatial and temporal correlations (Kopp and Morrison 2018). Additionally for the "Voronoi diagram" (Duthinth et al. 2018), it is proposed to automatically assign tributary areas to irregularly spaced pressure taps for area-averaged pressures. Comparing the tributary areas determined by the "Voronoi diagram" and the current traditional method, the differences are not very significant, which may induce similar final results. Accordingly, once the computer-derived structural loads of main frames (e.g., shear force and bending moment) have been obtained, they are converted in non-dimensional form as force $\left(C_{\mathrm{SF}}\right)$ or moment $\left(C_{\mathrm{BM}}\right)$ coefficients, as follows:

$$
\begin{aligned}
C_{\mathrm{SF}} & =\frac{C_{\mathrm{SF}, \text { computer }}}{\mathrm{W} \cdot \mathrm{B}} \\
C_{\mathrm{BM}} & =\frac{C_{\mathrm{BM}, \text { computer }}}{\mathrm{W}^{2} \cdot \mathrm{B}}
\end{aligned}
$$

where $C_{\mathrm{SF} \text {, computer }}$ and $C_{\mathrm{BM}}$, computer are the computer-derived shear force and bending moment values; $\mathrm{W}$ is the frame span (in the direction parallel to the frame plan) and equal to $10 \mathrm{~m}$; $B$ denotes the tributary bay widths, which are $5 \mathrm{~m}$ and $7.5 \mathrm{~m}$ for the gable- and hip-roofed cases, respectively.

According to the time history of force and moment coefficients, the peak windinduced structural loads can be evaluated by using the Sadek and Simiu (2002) method. This non-Gaussian translational approach conveniently considers the entire information of resulting time history and has been found to be acceptable for the peak estimation of internal forces in low-rise buildings for current cases (Sadek et al. 2004).

The results of two-dimensional (2D) linear models by using the windPRESSURE software package (Main and Fritz 2006) have been used to obtain a general comparison and reference. During the calculation, cladding and secondary members (i.e., purlin and girt) only transfer wind loads acting on building surfaces to the main frames which have the same geometry and material parameters in Table 2 . Then, the internal forces of main 
frames can be obtained by using influence line coefficients without considering the contribution of cladding and secondary members in the analysis of building main frames. This data-assisted method has been applied in other research studies (Mensah et al. 2011; Habte et al. 2017). Note that the resulting Directional Influence Factors (DIFs) in the windPRESSURE, which give the peak values of each response quantity of interest corresponding to unit wind speeds from different wind directions (Rigato et al. 2001), have been converted to coefficients equivalent to the force and moment coefficients in Eqs. (2)-(3).

\section{Wind-induced cladding loads}

Figures 5 (a)-(b) present the most critical positive and negative wind pressure coefficient contours regardless of wind direction, respectively. The peak values on the cladding were estimated by the translation method of Hermite, based on the full-scale 0.5-hour time history of wind pressure coefficients at each pressure tap (Yang et al. 2013; Ding and Chen 2014; Ding and Chen 2015). The estimations were found to be always reliable for the wind pressures with mildly or strongly non-Gaussian characteristics for the present low building configurations (Shao et al. 2018). In these figures, the critical wind directions corresponding to the most critical results are also plotted by arrows.

As expected, positive pressures are more considerable on wall surfaces for the current building geometries. Commonly, high positive pressure coefficients, as much as +2.8 , occur around the upper horizontal edges and corners of walls acted by slightlyoff perpendicular wind. The positive pressures decrease gradually for the areas closer to the ground. In addition to these normal cases, particular wind pressure distributions are found on the inside side walls near building re-entrant corners of L- and T-shaped buildings. For example, "Wing A" of Model-LH1, see Fig. 5 (a), shows large positive pressures concentrated on the upper edge near the end wall under similar perpendicular wind directions. However, distinctive pressures with considerable magnitudes are distributed in areas at intermediate heights close to the building re-entrant corner. The 
critical wind directions are no longer perpendicular to the inside side wall of the "Wing A" but become parallel cases. These may be induced by the downwind perpendicular building wing ("Wing B"), which blocks air movement and then changes the flow direction to act perpendicularly on the adjacent upwind wing ("Wing A"). Consequently, although the wind blows parallel to the side wall of the "Wing A", the inside area of the side wall near the building re-entrant corner is actually subjected to the perpendicular wind flow, which should be noted considering the particular building plan impact.

Regarding the negative wind pressure, the roof pressure characteristics have been comprehensively analyzed in Shao et al. (2018). Generally, the most considerable suction is induced at the lees of roof gable-end edges, ridge lines and corner of the gable-roofed building. Regarding the hip-roofed cases of non-rectangular plans, in addition to the previously mentioned cases, particularly high suctions appear along the eave edges near the building re-entrant corners for oblique wind directions. In terms of negative wall pressure (suction) on rectangular buildings, large magnitude suction is found at perpendicular edges connecting end and side walls along the wall height, in the cases of wind directions nearly perpendicular to windward walls, as also mentioned by Gavanski and Uematsu (2014). Away from the perpendicular edges, the wall suction reduces gradually. Regarding the L- and T-shaped buildings, the aforementioned findings are also applicable to the end walls and outside side walls (relative to building re-entrant corners). However, for the inside side walls, the critical areas with high suction are located around the upper horizontal wall edges near building re-entrant corners rather than the perpendicular edges of end walls away from building re-entrant corners. Note that the critical wind directions are oblique and are applied on leeward side walls, other than the common cases - perpendicular to windward walls.

Finally, the aspect ratio effects on positive and negative wind pressures of walls and roofs are found minimal. 

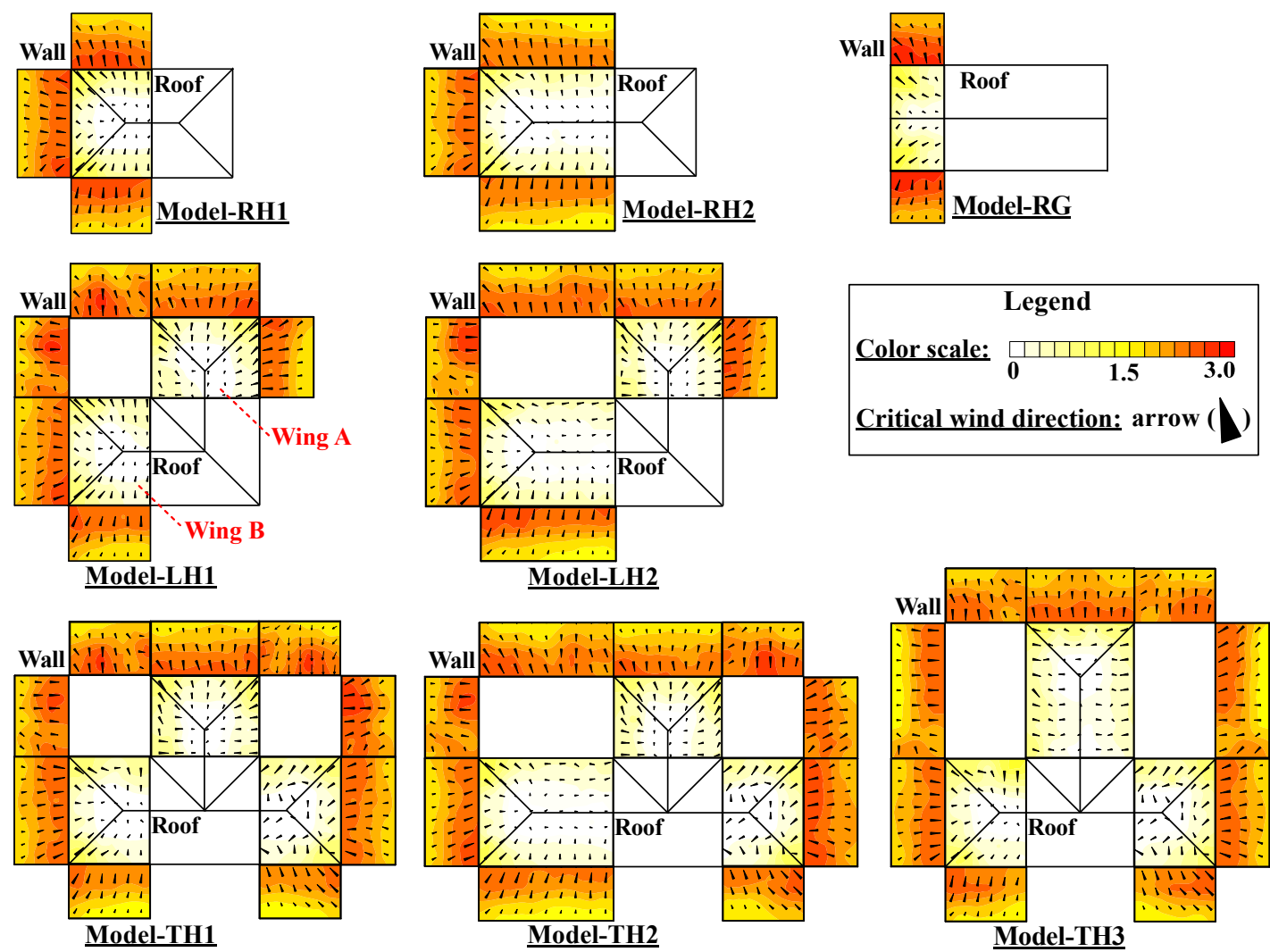

(a)
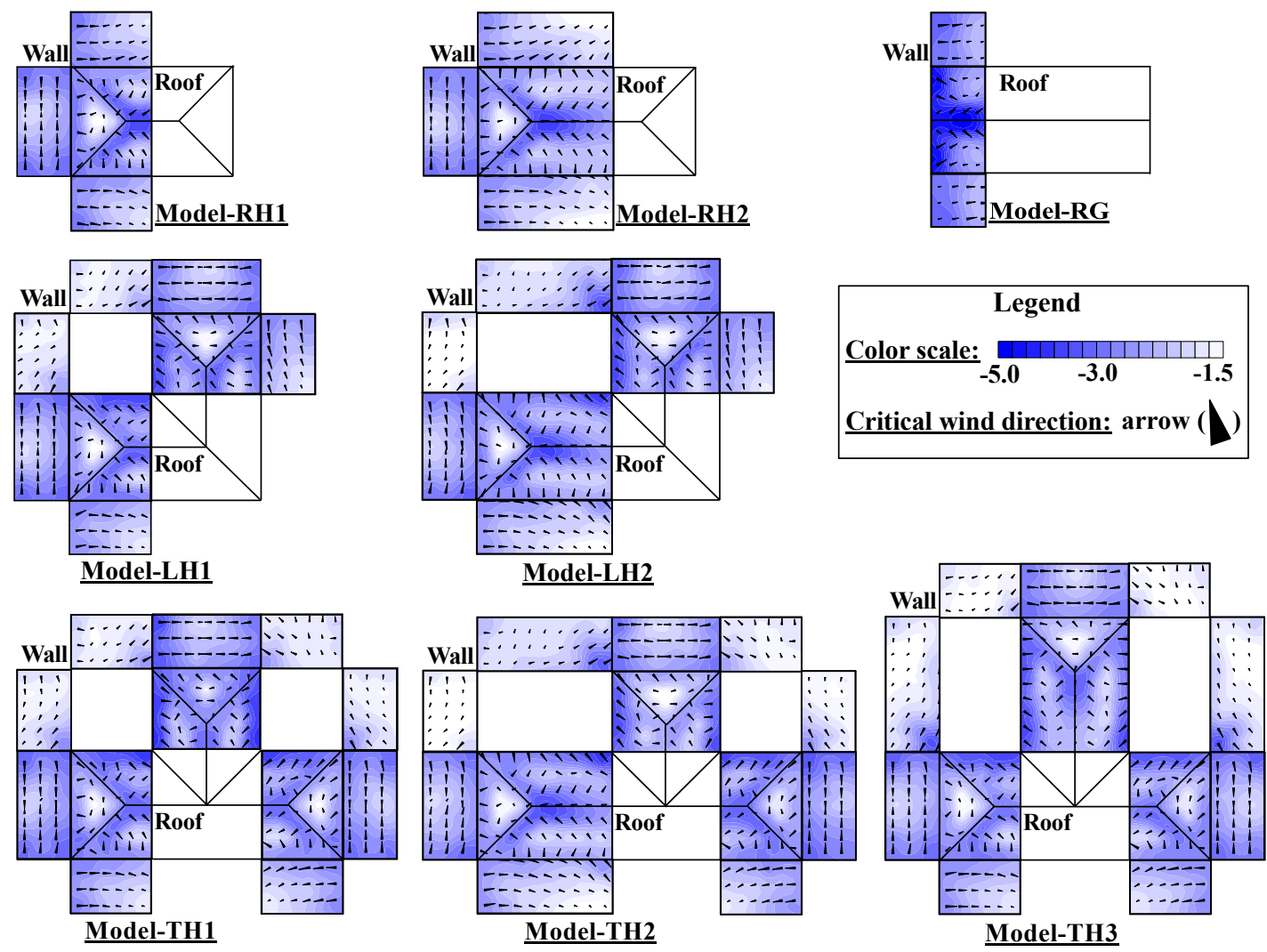

(b)

Fig. 5 Most critical wind pressure coefficient and critical wind direction distributions for cladding: (a) positive pressure, (b) negative pressure. 


\section{Wind-induced frame loads}

In this section, the features of wind-induced frame loads (i.e., shear forces and bending moments in the planes of frames), which are important for structural design are investigated. Note that for clear comparison, the peak force/moment coefficients, determined according to section 3.3, are normalized by the following absolute values of the corresponding most critical force/moment coefficients of the building ModelRH1 regardless of wind direction, i.e.,

$$
\begin{gathered}
\text { Normalized peak }\left|C_{\mathrm{SF}, \text { hip(gable)-roofed }}\right|=\frac{\left|\hat{C}_{\mathrm{SF}, \text { at } i \text { location of } j \text { frame, hip(gable)-roofed }}\right|}{\left|\hat{C}_{\mathrm{SF}, \text { at } i \text { location of } j \text { frame, RH1, for pinned case }}\right|} \\
\text { Normalized peak }\left|C_{\mathrm{BM}, \text { hip(gable)-roofed }}\right|=\frac{\left|\hat{C}_{\mathrm{BM}, \text { at } i \text { location of } j \text { frame, hip(gable)-roofed }}\right|}{\left|\hat{C}_{\mathrm{BM}, \text { at } i \text { location of } j \text { frame, RH1, for pinned case }}\right|}
\end{gathered}
$$

where $\quad|\cdot|$ denotes absolute value; $\hat{C}_{\mathrm{SF} \text {, at } i \text { location of } j \text { frame, hip(gable)-roofed }}$ and $\hat{C}_{\mathrm{BM} \text {, at } i \text { location of } j \text { frame, hip(gable)-roofed }}$ are the peak/most critical shear force and bending moment coefficients at the $i$ location (e.g., base or knee) of $j$ frame (e.g., end, intermediate or penultimate frames) of hip- or gable-roofed buildings, respectively; Accordingly, $\hat{C}_{\mathrm{SF} \text {, at } i \text { location of } j \text { frame, RH1, for pinned case }}$ and $\hat{C}_{\mathrm{BM}}$, at $i$ location of $j$ frame, RH1, for pinned case are the peak/most critical shear force and bending moment coefficients at the $i$ location of $j$ frame of building Model-RH1, respectively.

\subsection{Peak frame load variation with wind direction}

Figures 6-7 respectively show the normalized peak shear force and bending moment coefficient variations as a function of wind direction, for some unfavorable locations (e.g., shear forces at bases or bending moments at frame knees) for different main frames. As mentioned previously, the resulting coefficients have been normalized. For example, the shear force coefficients at the base of end frames [as depicted in Fig. 6 (a)], the peak result at the examined location for each wind direction is modified to an absolute value and divided by the absolute value of the most critical shear force coefficient at the corresponding similar location for the Model-RH1 in the pinned case 
(i.e., $\left|\hat{C}_{\mathrm{SF} \text {, at base of end frame, RH1, for pinned case }}\right|$ ). In terms of other results and figures, similar normalization is performed. It should also be noted that the denominator for different cases used in Eqs. (4) and (5) have the following relationship,

$$
\begin{aligned}
& \left|\hat{C}_{\mathrm{SF}, \text { at base of end frame, RH1, for pinned case }}\right| \\
= & 0.27 \cdot\left|\hat{C}_{\mathrm{SF}, \text { at base of intermediate frame, RH1, for pinned case }}\right| \\
= & 0.50 \cdot\left|\hat{C}_{\mathrm{SF}, \text { at base of penultimate frame, RH1, for pinned case }}\right| \\
& \mid \hat{C}_{\mathrm{BM}} \text { at knee of end frame, RH1, for pinned case } \mid \\
= & 0.58 \cdot \mid \hat{C}_{\mathrm{BM}} \text {, at midspan of intermediate frame, RH1, for pinned case } \mid \\
= & 0.78 \cdot \mid \hat{C}_{\mathrm{BM}} \text {, at knee of penultimate frame, RH1, for pinned case } \mid
\end{aligned}
$$

which implies that the intermediate frame sustains more wind-induced shear force and bending moment for the current case, due to a larger sharing of wind loads.

It is clear from Fig. 6 that for the shear forces at the bases of the rectangular gableroofed building $(\mathrm{RG})$, the peak loads are increased by about 7-8 times for both fixed and pinned cases for $45^{\circ}$ wind direction. More importantly, if concentrating on the results of 2D analysis obtained by the windPRESSURE [as sketched by Model-RG (2D) in Fig. 6] for a bare frame, higher peak values occur, roughly two (2) times larger than those of the current 3D model (RG). However, their variation patterns show some similarities for the full model and bare frame. In fact, two successive peaks appear around $45^{\circ}$ and $135^{\circ}$ wind directions, for which the windward case $\left(45^{\circ}\right.$ wind $)$ is more critical with larger shear force. The considerable magnitude increases between the rectangular gable-roofed and hip-roofed buildings are mainly attributed not only to the more critical cladding loads but also to the frame arrangement of the Model-RG.

Considering the building plan effect of hip-roofed buildings, the results of the Lshaped building (LH1) and the side wing of T-shaped building [TH1(S)] perform similarly in variation patterns and magnitudes, which are different from the rectangular hip-roofed case (RH1). Specifically, for wind directions from $40^{\circ}$ to $90^{\circ}$, the increase in the peak coefficients of LH1 and TH1(S) is around 50\%, compared with those of RH1. Accordingly, the critical wind directions are commonly increased by around $20^{\circ}$. 
In addition to the influence on result patterns, the peaks are similar for those cases mentioned previously. Furthermore, regarding the central wing of T-shaped building $[\mathrm{TH} 1(\mathrm{C})]$, the results show random characteristics and generally fall in the range between those of the Model-LH1 and Model-RH1, due to the impact of side wings. Since all produced data are based on the same computational model by using different cladding loads, the aforementioned force variations are attributed to the cladding loads. However, the responses of main frames, due to the significantly variable cladding loads on local areas (e.g., positive pressure or suction around building re-entrant corners) are attenuated owing to the reduced spatial-temporal correlation of cladding pressures on multiple building surfaces, as mentioned by Kopp and Morrison (2018).

In terms of bending moments, as indicated in Fig. 7, most findings and conclusions are similar to those of shear forces discussed previously. Particularly for the frame knees $(\mathrm{F} / \underline{\mathrm{F}})$ of penultimate frames near building re-entrant corners, nearly $20 \%$ increases of the bending moment effects are found for the Model-LH1 and TH1 (side wing), compared with those of the Model-RH1 and TH1(C). This indicates the impact of the more considerable cladding loads on the building surfaces adjacent to these frames. 


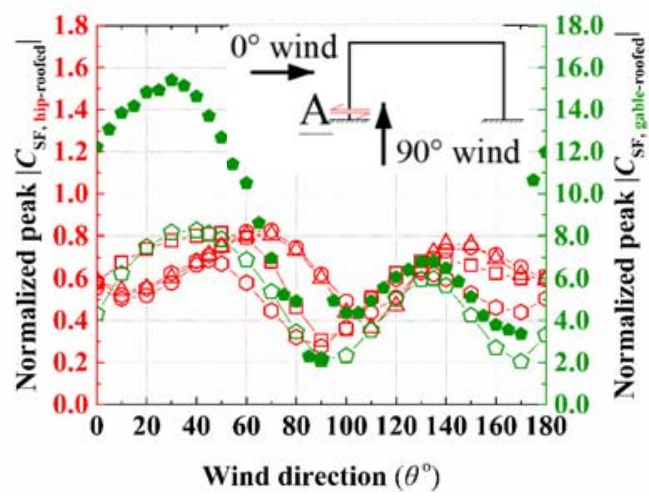

(a)
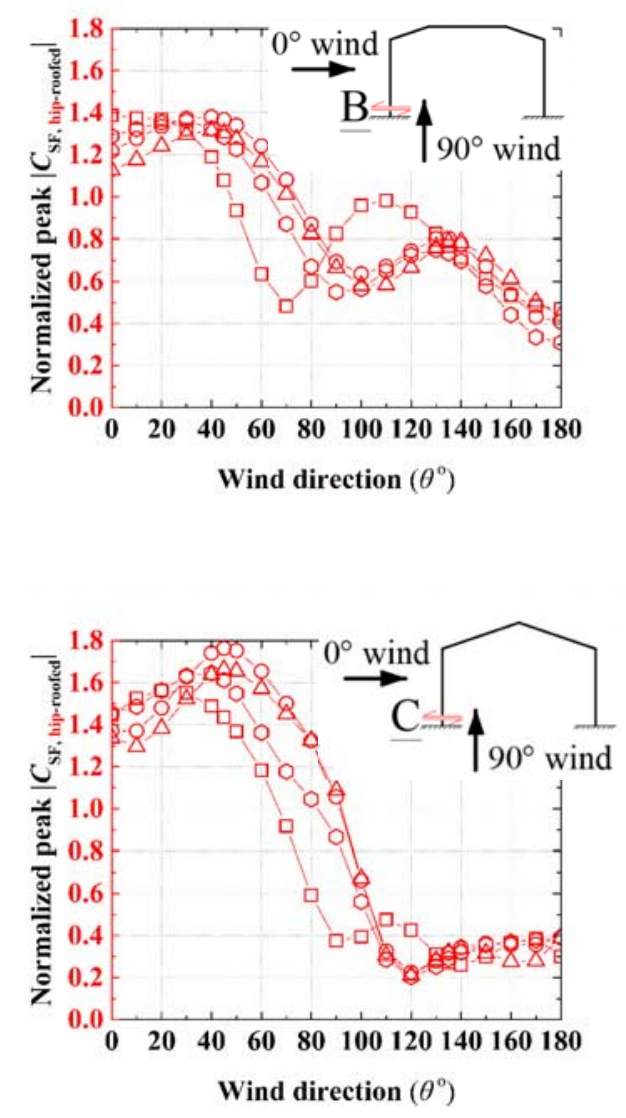

(c)

(b)
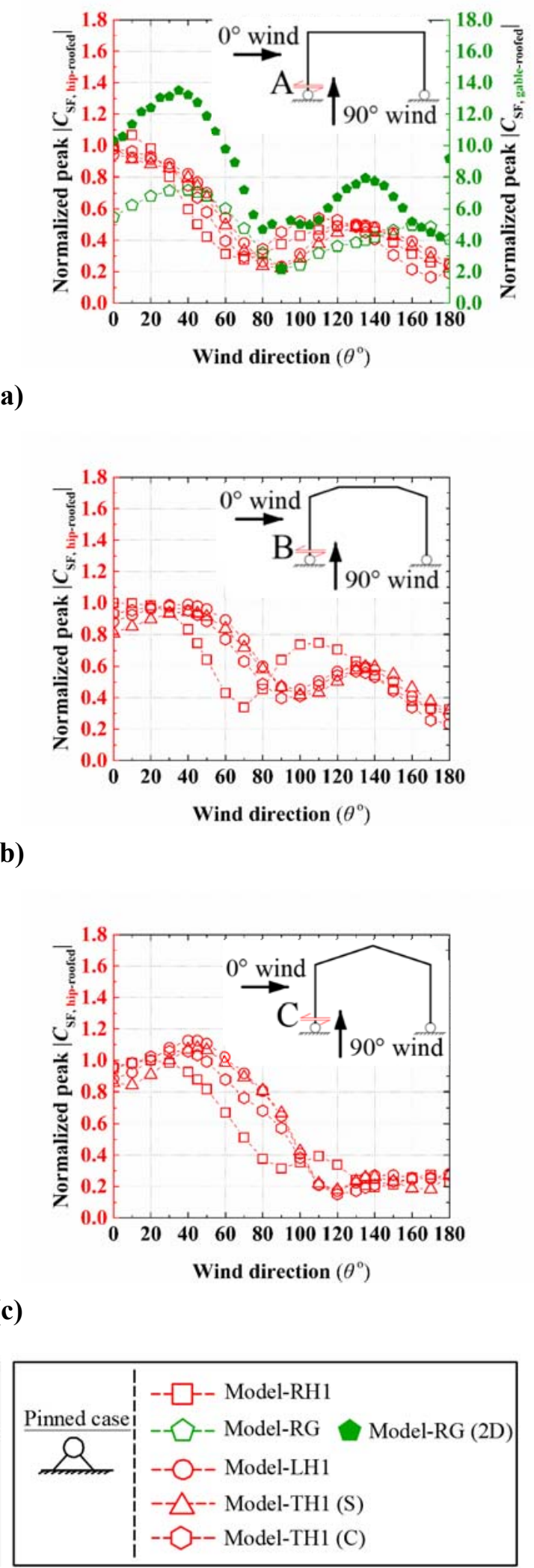

(d)

Fig. 6 Peak shear force coefficient variations as a function of wind direction: (a) at base $A / \underline{A}$ of end frame, (b) at base $B / \underline{B}$ of intermediate frame, (c) at base $C / \underline{C}$ of penultimate frame, (d) legend. 


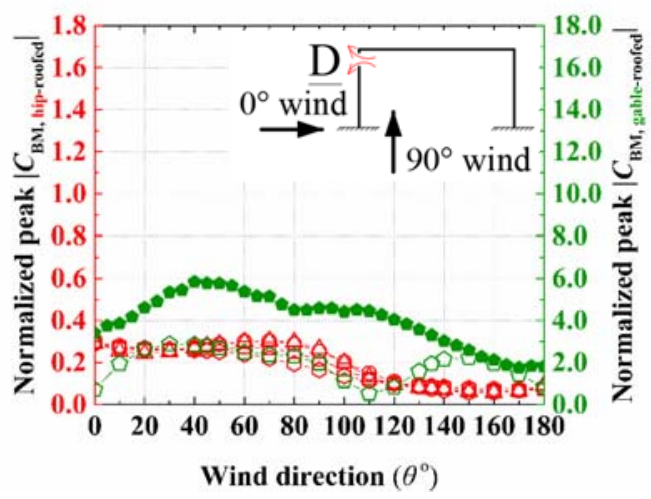

(a)
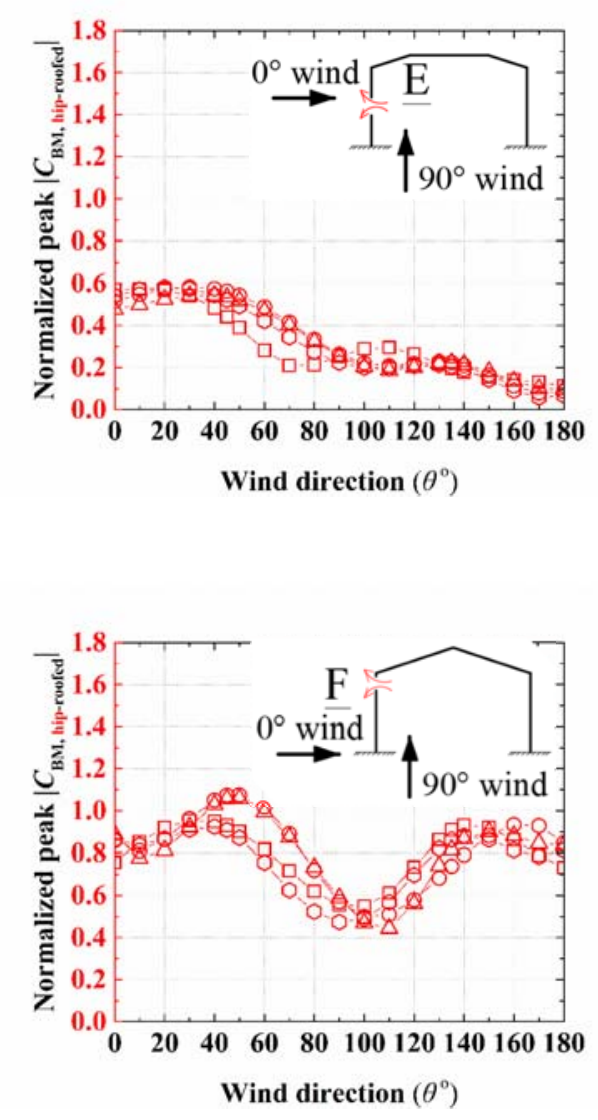

(b)
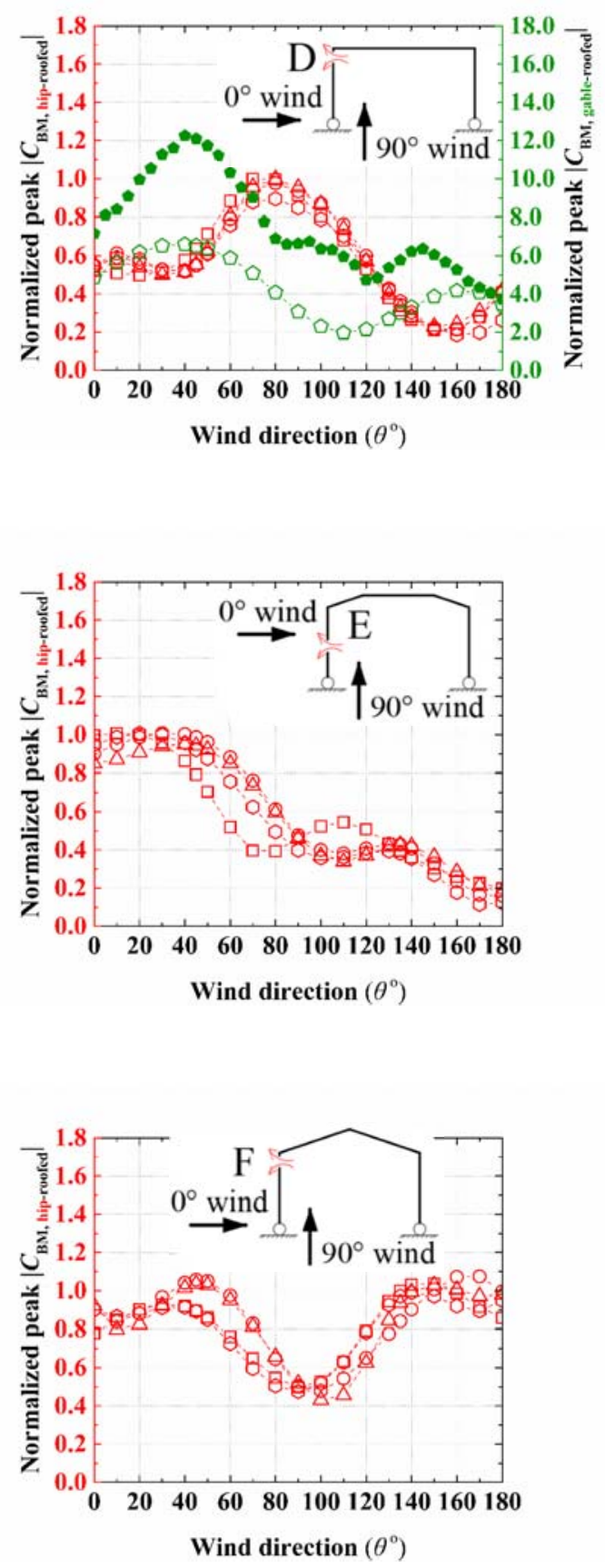

(c)

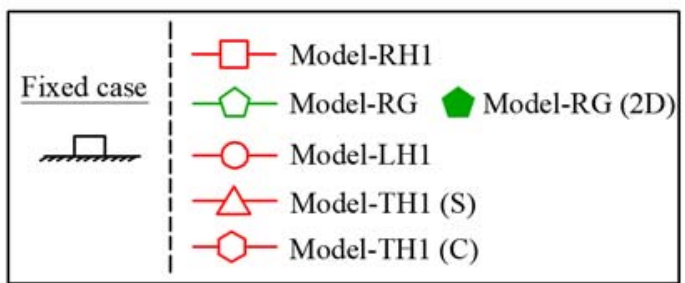

(d)

Fig. 7 Peak bending moment coefficient variations as a function of wind direction: (a) at knee $D / \underline{D}$ of end frame, (b) at mid-span $E / \underline{E}$ of intermediate frame, (c) at knee $\mathrm{F} / \underline{\mathrm{F}}$ of penultimate frame, (d) legend. 


\subsection{Effect of aspect ratios}

In addition, more building models and wings are considered to examine the aspect ratio effects on the wind-induced structural load variations, by utilizing the overall data ranges for the critical frame locations analyzed in section 5.1. For each frame case, the normalized coefficient ranges are synthesized by the maximum and minimum values for all wind directions, as shown in Figs. 8-9. Each result symbol group includes two cases of similar wings for building models with different aspect ratios. It is seen that the data ranges are moderately influenced by the different building aspect ratios. Moreover, the most critical values generally decrease when increasing the aspect ratios for most cases of shear force and bending moment coefficients. On this issue, the conclusions for structural loads are similar to those for cladding loads. 

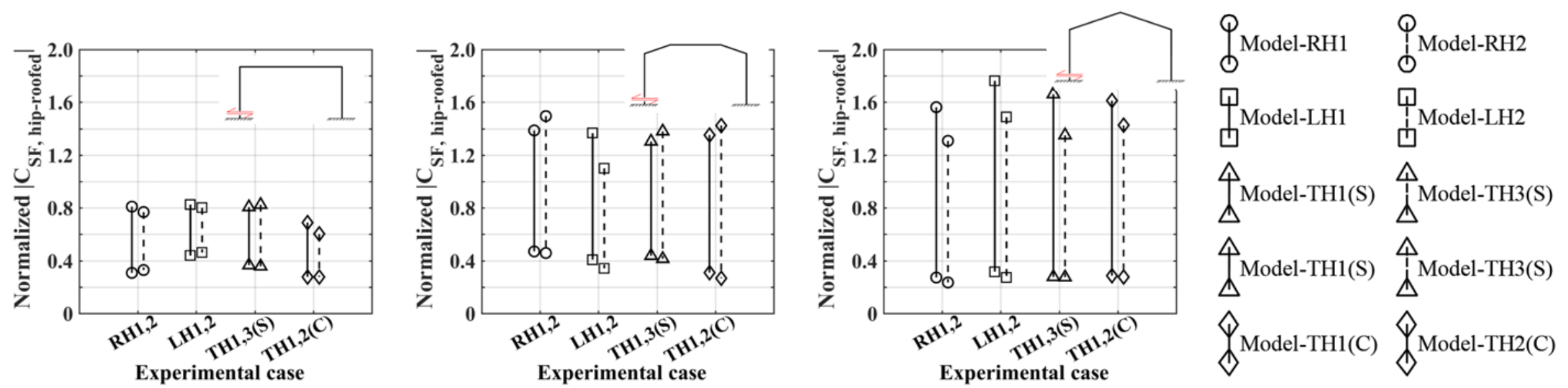

(a)
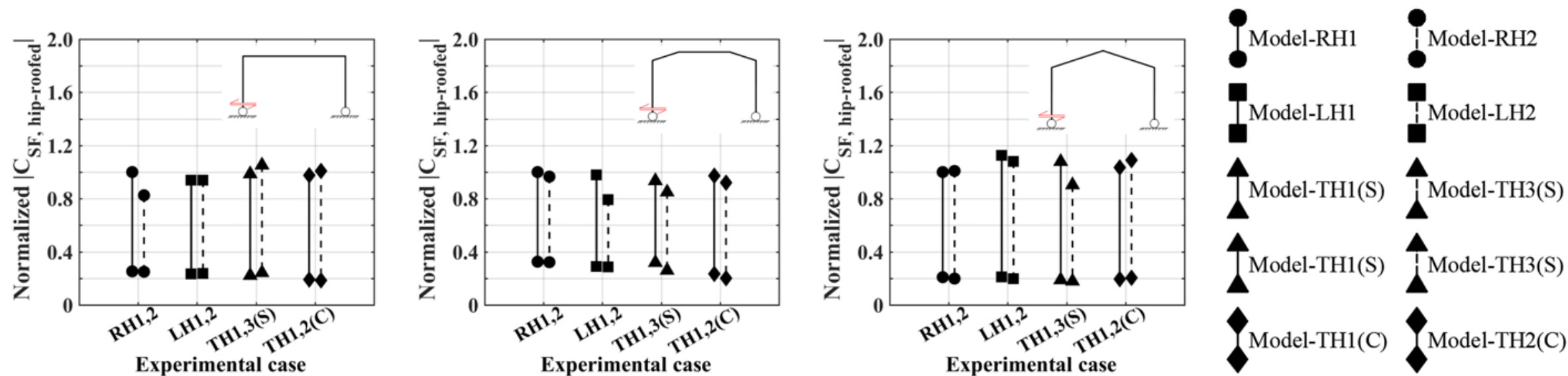

(b)

Fig. 8 Ranges of normalized peak shear force coefficients $\mid C_{\mathrm{SF}}$, hip-roofed $\mid$ for end, intermediate and penultimate frames of hip-roofed models with different aspect ratios: (a) fixed case, (b) pinned case. 

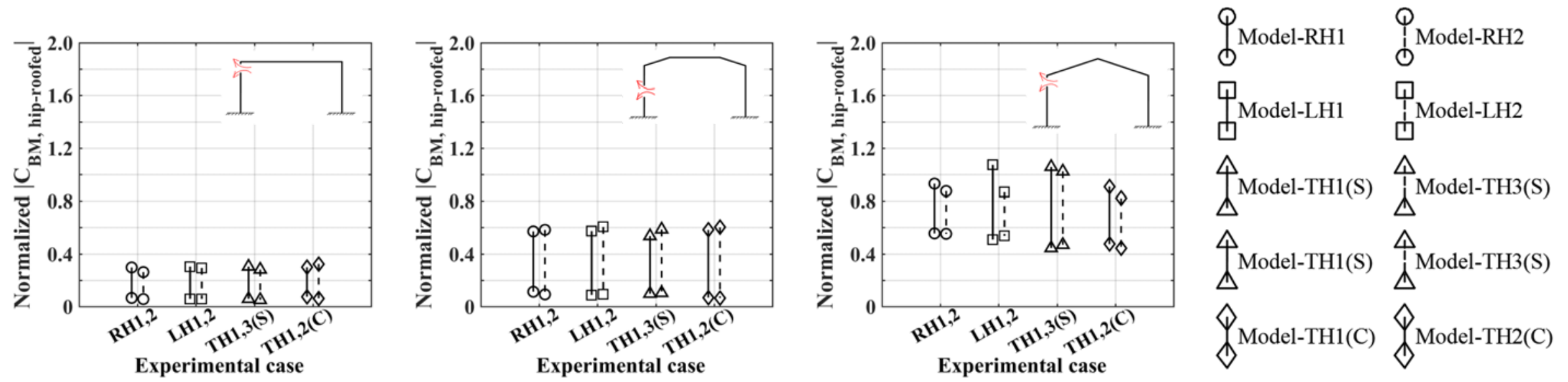

(a)
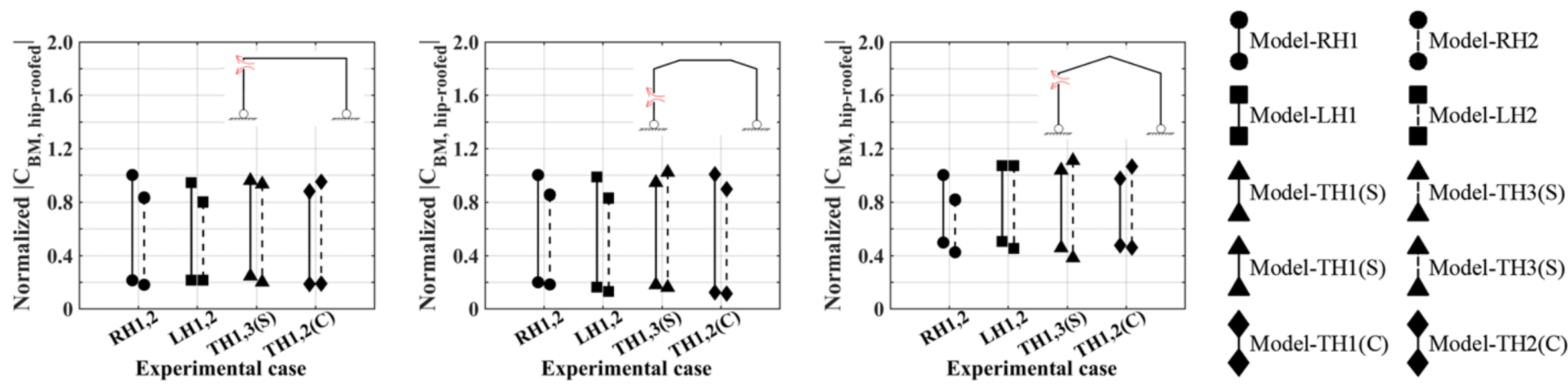

(b)

Fig. 9 Ranges of normalized peak bending moment coefficients $\mid C_{\mathrm{BM}}$, hip-roofed $\mid$ for end, intermediate and penultimate frames of hip-roofed models with different aspect ratios: (a) fixed case, (b) pinned case. 


\subsection{Most critical frame load distribution for the rectangular gable-roofed building}

After examining the local structural load features under different wind directions, Fig. 10 presents the most critical normalized shear force and bending moment coefficient distributions for the end frame of Model-RG, regardless of wind direction. Note that the most critical coefficients on the end frame of Model-RH1 in the pinned case are used for normalization. Considering the shear force [as seen in Fig. 10 (a)], the connection and boundary conditions make significant contributions to the structural load distribution. Regarding the fixed case, the frame bases are a considerably unfavourable area with largest shear force, similar to those of the pinned case. However, for the pinned case, in addition to the frame bases, the frame knees are also subjected to a significant shearing action. In terms of bending moment, more critical results occur around the bases and knees for the fixed case and knees for the pinned case.

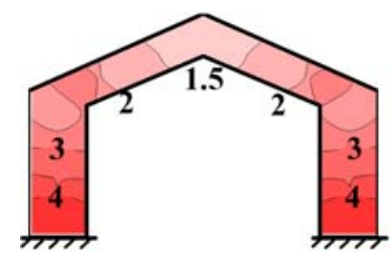

Fixed case

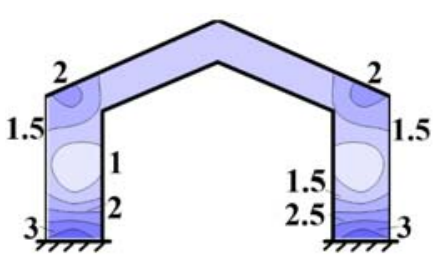

Fixed case

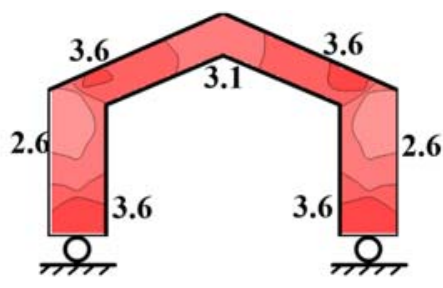

Pinned case

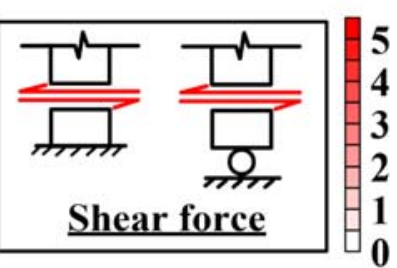

(a)

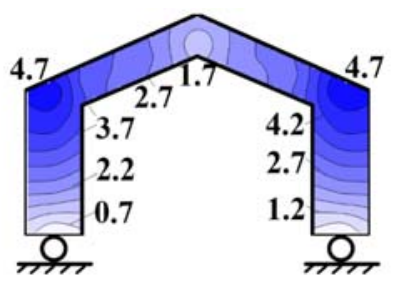

Pinned case

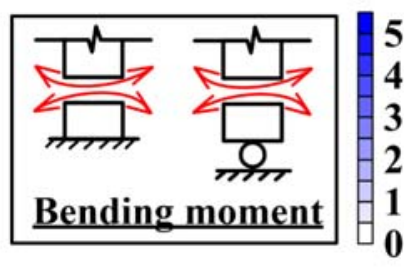

(b)

Fig. 10 Most critical normalized coefficients on the end frame of the rectangular gable-roofed building for fixed and pinned cases: (a) shear force, (b) bending moment.

Since all the results shown in Fig. 10 are normalized by the most critical values of the rectangular hip-roofed building model (RH1), the building plan effect is clear, by the comparison. Generally, four (4) times larger structural loads act on the critical area including base and knees of the Model-RG. This is also mainly induced by the 
considerable surface wind pressure and the frame arrangement of Model-RG, in comparison with Model-RH1.

\subsection{Most critical frame load distribution for the hip-roofed buildings}

This section shows the most critical structural load distributions of three main frames for all hip-roofed buildings, including the normalized shear force and bending moment coefficients, as presented by Figs. 11 and 12, respectively. The normalization is made by dividing the most critical coefficients of the corresponding case. For example, regarding the end frame, the most critical peak shear force coefficient of Model-RH1 is used as the reference for all results of end frames for all models. Similarly, the reference values applied to different frames have the relationship indicated by the following equations.

$$
\begin{aligned}
& \left|\hat{C}_{\mathrm{SF}, \text { end frame, RH1, for pinned case }}\right| \\
= & 0.38 \cdot\left|\hat{C}_{\mathrm{SF}, \text { intermediate frame, RH1, for pinned case }}\right| \\
= & 0.55 \cdot\left|\hat{C}_{\mathrm{SF}, \text { penultimate frame, RH1, for pinned case }}\right| \\
& \left|\hat{C}_{\mathrm{BM}, \text { end frame, RH1, for pinned case }}\right| \\
= & 0.75 \cdot\left|\hat{C}_{\mathrm{BM}, \text { intermediate frame, RH1, for pinned case }}\right| \\
= & 0.93 \cdot\left|\hat{C}_{\mathrm{BM}, \text { penultimate frame, RH1, for pinned case }}\right|
\end{aligned}
$$

Note that the factors here are different from those in Eqs. (6)-(7), since the denominators used for the normalization change. Also, it is verified again that more considerable frame loads act on the intermediate frames among all the frames.

For the shear effect as indicated in Fig. 11, large values are generally found around the frame bases and the knees, connecting columns and beams. Moreover, the shear forces are commonly mutated at purlin and girt attachments along frames. The connection of structural members and boundary conditions significantly influence the shear force magnitudes and the distribution shapes for the pinned and fixed cases. For the Model-RH1 in the pinned case as an example, the maximum shear forces around knees of end and penultimate frames increase on average by $20 \%$, compared with those of the fixed cases. In addition, the shear forces of the L- and T-shape cases are different 
from those of the rectangular case (Model-RH1), particularly for the Model-LH1 and Model-TH1(S). Due to the unsymmetrical building plan, the non-rectangular building models sustain distinctive cladding loads, which further influence the frame load distributions. Specifically for left and right knees of the intermediate frames for ModelLH1 and Model-TH1(S), the maximum shear forces are smaller and larger than those of the Model-RH1 by around 20\%, respectively [see Fig. 11 (b)]. Basically, the left and right knees in Figs 11-12 correspond to the knees away from and near the building reentrant corners, respectively. Therefore, the shear forces are intensified for those frames near the building re-entrant corners.

As far as bending moments are concerned, they also perform differently for the fixed and pinned frame cases. Generally, due to the decrease of the overall stiffness, buildings under the pinned cases are acted by higher bending moment effects, as seen in Fig. 12. Furthermore, different bending moment distributions are observed for the fixed and pinned cases, due to the different boundary conditions. For instance, for the columns of intermediate frames in Fig. 12 (b), the maximum bending moments act at the column bases for the fixed case rather than that at the mid-span of columns for the pinned cases. Moreover, the column bending moments for the fixed case decrease to zero close to one third of the column height above the ground and inversely increase to the maximum at the base. However, the maximum bending moments at the column mid-spans reduce gradually toward the base for the pinned case. The building plan effect is also clear particularly for the right knees of the intermediate and penultimate frames for the pinned cases with a maximum $25 \%$ increase. 

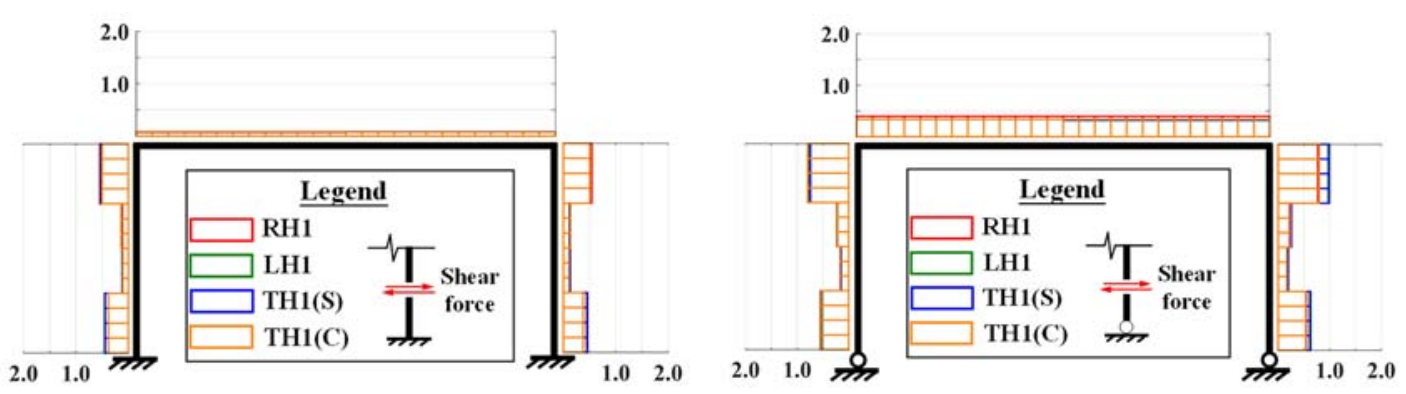

(a)
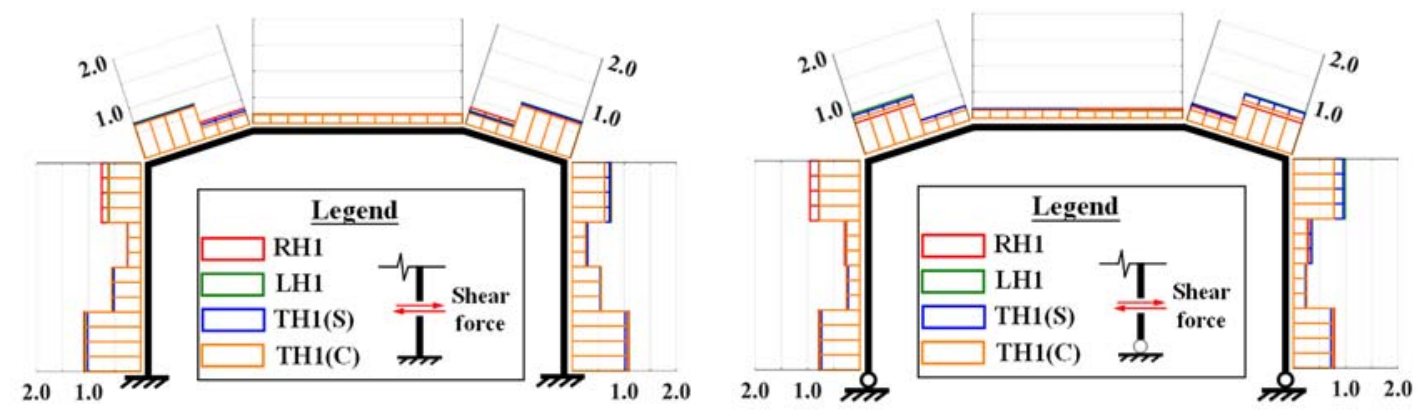

(b)
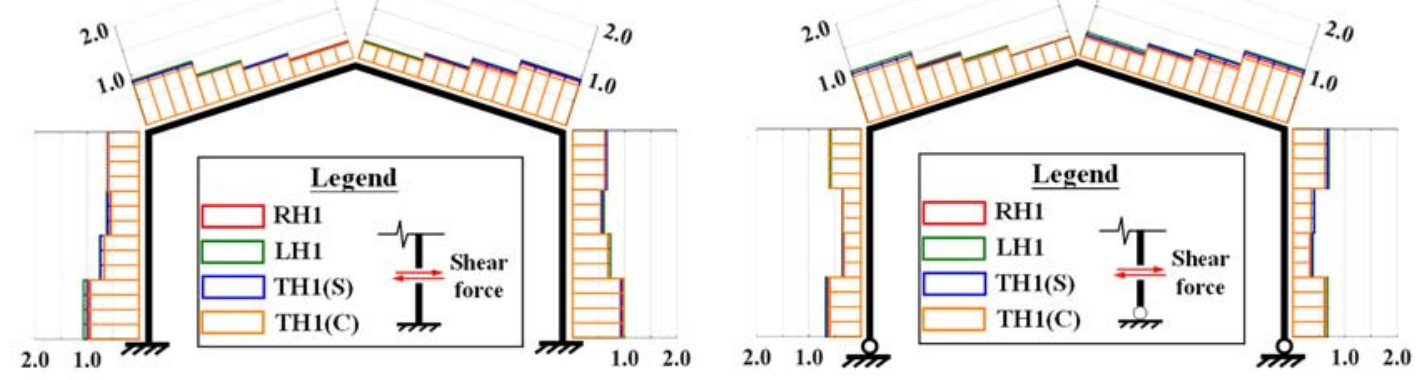

(c)

Fig. 11 Most critical normalized shear force coefficients on the different frames of the hip-roofed buildings for fixed and pinned cases: (a) end frame, (b) intermediate frame, (c) penultimate frame. 

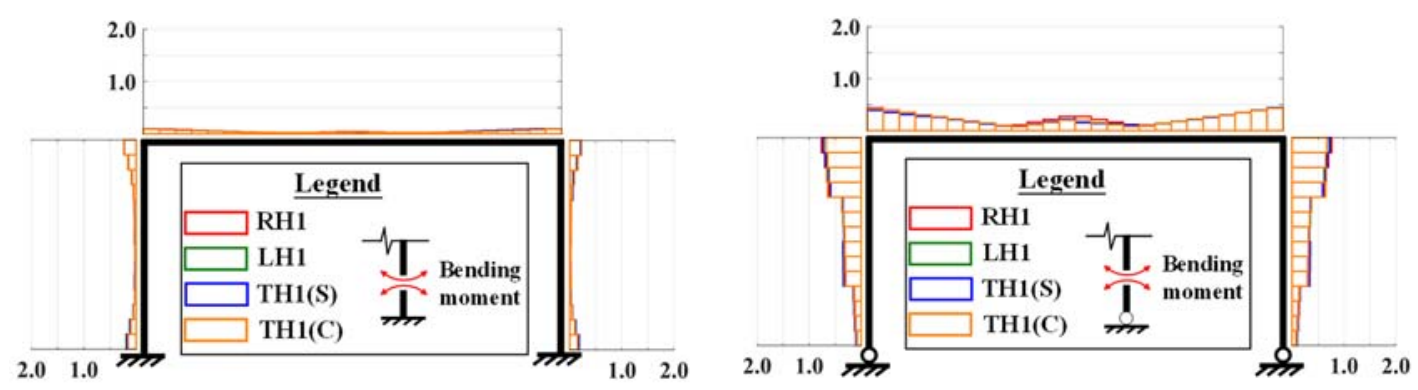

(a)
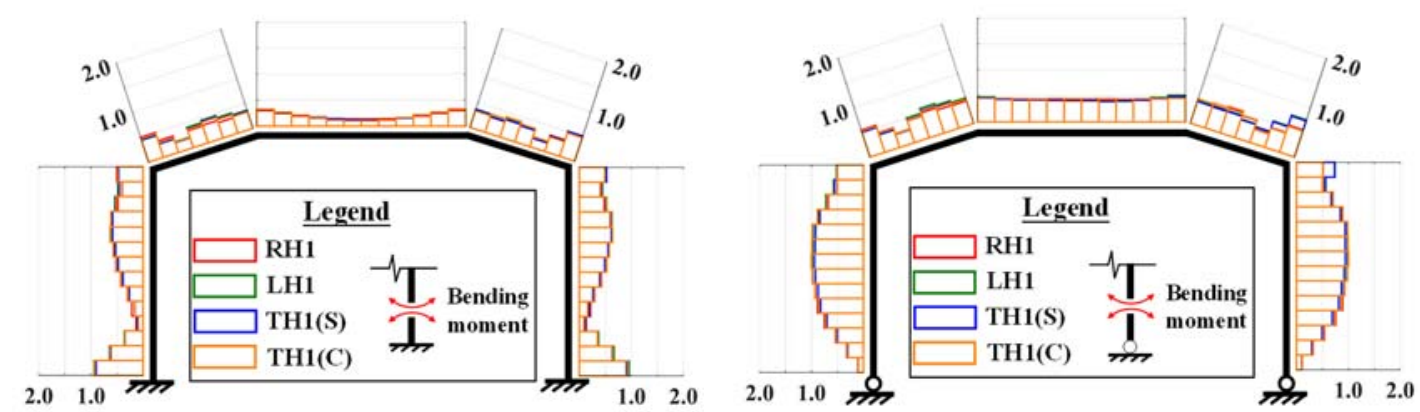

(b)
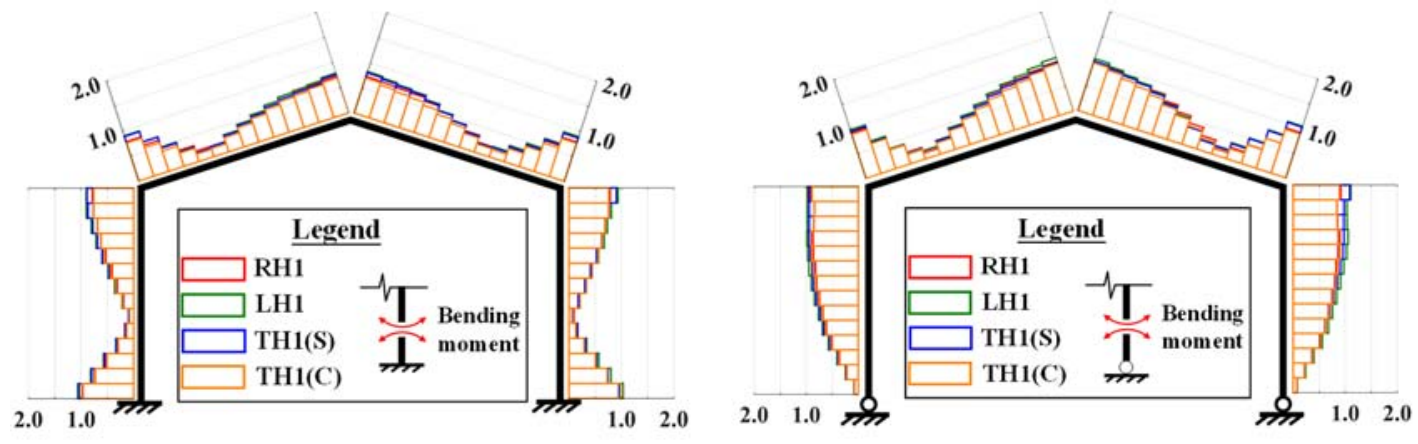

(c)

Fig. 12 Most critical normalized bending moment coefficients on the different frames of the hip-roofed buildings for fixed and pinned cases: (a) end frame, (b) intermediate frame, (c) penultimate frame. 


\section{Summary and Conclusions}

The characteristics of cladding and structural loads for hip-roofed low-rise buildings with rectangular, L- or T-shaped plans are considered in the paper, based on the experimental wind tunnel data and three-dimensional computational finite element modeling. Comprehensive parameters including building geometries (i.e., roof shape, building plan and horizontal aspect ratio) and structural system features (i.e., frame arrangement, connection conditions of structural members and boundary) are investigated.

Regarding the cladding loads, the roof pressures are together controlled by roof shapes and building plans. Considering the roof shape effect, the rectangular gable roof incurs more considerable suction, compared with the rectangular hip roof. However, distinctively large suction are also subjected by eaves of the L- and T-shaped hip roofs around the building re-entrant corners. Additionally, for the wall pressure, it is mainly influenced by building plans, particularly for the inside side walls near building reentrant corners of L- and T-shaped buildings, which may be subjected to considerable positive and negative pressure actions under particular oblique wind directions.

In terms of structural loads, they are integrally presented for hip-roofed low buildings and can be summarized as follows:

(1) Compared with the gable-roofed case, the shear force and bending moment coefficients for hip-roofed buildings decrease significantly. Furthermore, the intermediate frames of hip-roofed buildings sustain more wind-induced structural loads for the currently tested cases, compared with the other end and penultimate frames. Moreover, the column bases and frame knees are acted by higher structural loads for all frames of both gable- and hip-roofed cases.

(2) Considering the building plan effect of hip-roofed buildings on result patterns, for wind directions from $40^{\circ}$ to $90^{\circ}$, the increase in the peak coefficients of the L-shaped hip-roofed building and side wing of the corresponding T-shaped case is around $50 \%$, compared with those of the rectangular hip-roofed case. 
Furthermore, the critical wind directions are commonly increased by around $20^{\circ}$. The building plan impact is also clear for peak magnitudes. The most critical structural loads around knees of the intermediate and penultimate frames near the building re-entrant corners for the pinned cases show a maximum of $25 \%$ increase. Finally, regarding the central wings of T-shaped buildings, their results generally fall in the ranges between the rectangular and L-shaped buildings.

(3) The connection of structural members and boundary conditions significantly influence the structural load coefficients and the distribution shapes. For the rectangular hip-roofed building in the pinned case as an example, the maximum shear forces around knees of end and penultimate frames increase on average by $20 \%$, compared with those of the fixed cases.

In addition, the influence of horizontal aspect ratios on both cladding and structural loads is found to be minimal.

Finally, this study has presented comprehensive features of cladding and structural loads on the hip-roofed low buildings based on real wind loads and accurate numerical models, to provide a necessary reference for wind-resisting design. More parameters, which may influence the current findings, and code provision applicability, will be examined in the near future.

\section{Acknowledgments}

The support provided by the 111 Project of China (B13002) and China Scholarship Council, China (CSC201507090037) for the first author's study at Concordia University (November 2015-May 2017) is gratefully acknowledged.

\section{Reference}

ABAQUS, 2014. ABAQUS/Standard, User's Manual, Hibbitt, Karlsson and Sorensen, Inc., Providence, R.I.

Alrawashdeh, H., Stathopoulos, T., 2015. Wind pressures on large roofs of low buildings and wind codes and standards. J. Wind. Eng. Ind. Aerodyn., 147, 212-225. 
Case, P.C., Isyumov, N., 1998. Wind loads on low buildings with 4:12 gable roofs in open country and suburban exposures. J. Wind. Eng. Ind. Aerodyn., 77-78, 107-118.

Coffman, B.F., Main, J.A., Duthinh, D., Simiu, E., 2009. Wind effects on low-rise metal buildings: Database-assisted design versus ASCE 7-05 standard estimates. J. Struct. Eng., 136(6), 744-748.

Díaz, C., Martí, P., Victoria, M., Querin, O.M., 2011. Review on the modelling of joint behaviour in steel frames. J. Constr. Steel Res., 67(5), 741-758.

Ding, J., Chen, X., 2014. Assessment of methods for extreme value analysis of non-Gaussian wind effects with short-term time history samples. Eng. Struct., 80, 75-88.

Ding, J., Chen, X., 2015. Moment-based translation model for hardening non-Gaussian response processes. J. Eng. Mech., 142(2), 06015006.

Duthinh, D., Main, J.A., Matthew, L., Gierson, M.L., Phillips, B.M., 2018. Analysis of wind pressure data on components and cladding of low-rise buildings. ASCE-ASME J. Risk Uncertainty Eng. Syst., Part A: Civ. Eng., 4(1), 04017032.

Duthinh, D., Main, J.A., Wright, A.P., Simiu, E, 2008. Low-rise steel structures under directional winds: Mean recurrence interval of failure. J. Struct. Eng., 134, 1383-1388.

Duthinh, D., William, P.F., 2007. Safety evaluation of low-rise steel structures under wind loads by nonlinear database-assisted technique. J. Struct. Eng., 133, 587-594.

Engineering Science Data Unit (ESDU), 1982. Strong winds in the atmospheric boundary layer. Part1. mean-hourly wind speeds. Data Item 82026.

Feng, C.D., Chen, X.Z., 2018. Characterization of translating tornado-induced pressures and responses of a low-rise building frame based on measurement data. Eng. Struct. 174, 495508.

Gavanski, E., Kordi, B., Kopp, G.A., Vickery, P. J., 2013. Wind loads on roof sheathing of houses. J. Wind. Eng. Ind. Aerodyn., 114, 106-121.

Gavanski, E., Uematsu, Y., 2014. Local wind pressures acting on walls of low-rise buildings and comparisons to the Japanese and US wind loading provisions. J. Wind. Eng. Ind. Aerodyn., 132, 77-91.

Ginger, J., Henderson, D., Humphreys, M., Konthesingha, C., Stewart, M.G., 2015. Wind loads on the frames of industrial buildings. Aus. J. Struct. Eng., 16(2), 169-178. 
Habte, F., Chowdhury, A.G., Zisis, I., 2017. Effect of wind-induced internal pressure on local frame forces of low-rise buildings. Eng. Struct. 143, 455-468.

Holmes, J.D., 1983. Wind loads on low-rise buildings—a review. Rep., Div. of Build. Res., Commonwealth Scientific and Industrial Research Organization (CSIRO), Melbourne, Australia.

Holmes, J.D., 1994. Wind pressures on tropical housing. J. Wind. Eng. Ind. Aerodyn., 53(1-2), $105-123$.

Hoxey, R.P., Robertson, A.P., 1994. Pressure coefficients for low-rise building envelopes derived from full-scale experiments. J. Wind Eng. Ind. Aerodyn., 53(1-2), 283-297.

Jang, S., 2004. Evaluation of ultimate strength of low-rise steel building frames and components using wind tunnel data, Lehigh University, Ph.D. Dissertation.

Kikuchi, H., Tamura, Y., Hibi, K., Suganuma, S., 2001. Local pressures acting on low-rise and middle-rise buildings with 1-shape plan. Proc., 5th Asia-Pacific Conf. on Wind Engineering, International Association for Wind Engineering.

Kopp, G.A., Mans, C., Surry, D., 2005. Wind effects of parapets on low buildings: Part 2. Structural loads. J. Wind Eng. Ind. Aerodyn., 93(11), 843-855.

Kopp, G.A., Morrison, M.J., 2018. Component and cladding wind loads for low-slope roofs on low-rise buildings, J. Struct. Eng., 144(4), 04018019.

Lin, J.X., Surry, D., Tieleman, H.W., 1995. The distribution of pressure near roof corners of flat roof low buildings. J. Wind. Eng. Ind. Aerodyn., 56(2-3), 235-265.

Mahendran, M., Moor, C., 1999. Three-dimensional modeling of steel portal frame buildings. J. Struct. Eng., 125(8), 870-878.

Main, J.A, Fritz, W.P., 2006. Database-assisted design for wind: concepts, software, and examples for rigid and flexible buildings. NIST Building Science Series 180, National Institute of Standards and Technology, Gaithersburg, MD.

Meecham, D., Surry, D., Davenport, A.G., 1991. The magnitude and distribution of windinduced pressures on hip and gable roofs. J. Wind. Eng. Ind. Aerodyn., 38(2-3), 257-272.

Mensah, A.F., Datin, P.L., Prevatt, D.O., Gupta, R., Van de Lindt, J.W., 2011. Database-assisted design methodology to predict wind-induced structural behavior of a light-framed wood 
building. Eng. Struct., 33, 674-684.

Parackal, K.I., Humphreys, M.T., Ginger, J.D., Henderson, D.J., 2016. Wind loads on contemporary Australian housing, Australian J. Struct. Eng., 17(2), 136-150.

Rigato, A, Chang, P, Simiu, E. 2001. Database-assisted design, standardization, and wind direction effects. J. Struct. Eng., 127(8), 855-860.

Sadek, F., Diniz, S., Kasperski, M., Gioffre, M., Simiu, E., 2004. Sampling Errors in the Estimation of Peak Wind-Induced Internal Forces in Low-Rise Structures. J. Eng. Mech., 130(2), 235-239.

Sadek, F, Simiu, E., 2002. Peak non-Gaussian wind effects for data base-assisted low-rise building design. J. Eng. Mech., 128(5), 530-539.

Salter, P.R., Malik, A.S., King, C.M., 2004. Design of single-span steel portal frames to BS 5950-1: 2000, SCI publication P252, Ascot: The Steel Construction Institute.

Shao, S., Stathopoulos, T., Yang, Q.S., Tian, Y.J., 2018. Wind pressures on 4-12-sloped hip roofs of L- and T-shaped low-rise buildings. J. Struct. Eng., 144(7), 04018088.

Stathopoulos, T., 1984a. Wind loads on low-rise buildings: a review of the state of the art. Eng. Struct., 6(2), 119-135.

Stathopoulos, T., 1984b. Design and fabrication of a wind tunnel for building aerodynamics. J. Wind. Eng. Ind. Aerodyn., 16(2-3), 361-376.

Stathopoulos, T., Zhou, Y.S., 1993. Numerical simulation of wind-induced pressures on buildings of various geometries. J. Wind. Eng. Ind. Aerodyn., 46\&47(93), 419-430.

Sockalingam, B., 1995. Wind load distribution in low-rise metal buildings. Clemson University, Ph.D. Dissertation.

St. Pierre, L.M., Kopp, G.A., Surry, D., Ho, T.C.E., 2005. The UWO contribution to the NIST aerodynamic database for wind loads on low buildings: Part 2. Comparison of data with wind load provisions. J. Wind. Eng. Ind. Aerodyn., 93(1), 31-59.

Wrzesien, A.M., Lim, J.B.P., Xu, Y., Macleod, I.A., Lawson, R.M., 2015. Effect of stressed skin action on the behaviour of cold-formed steel portal frames. Eng. Struct., 105, 123-136.

Wu, D., Yang, Q.S., Tamura, Y., 2015. Estimation of internal forces in cladding support components due to wind-induced overall behaviors of long-span roof structure. J. Wind. 
Eng. Ind. Aerodyn. 142, 15-25.

Yang, L., Gurley, K. R., and Prevatt, D. O., 2013. Probabilistic modeling of wind pressure on low-rise buildings. J. Wind. Eng. Ind. Aerodyn., 114, 18-26.

Yang, N., Bai, F., 2017. Damage analysis and evaluation of light steel structures exposed to wind hazards. Appl. Sci., 7(3), 239. 